\title{
The replicability crisis as chance for psychological research and South African Journal of Industrial Psychology
}

Author:
Alina S. Hernandez Bark ${ }^{1}$
Affiliation:
'Department of Social
Psychology, Faculty of
Psychology and Sport Science,
Institute of Psychology,
Goethe University Frankfurt,
Frankfurt am Main, Germany
Corresponding author:
Alina S. Hernandez Bark,
HernandezBark@ @sych.
uni-frankfurt.de
Dates:
Received: 31 July 2019
Accepted: 16 Nov. 2019
Published: 13 Dec. 2019
smart phone or
mowile device
to read online.
Hernandez Bark, A.S. (2019).
The replicability crisis as
chance for psychological
research and South African
Journal of Industrial
Psychology. SA Journal of
Industrial Psychology/SA
Tydskrif vir Bedryfsielkunde,
45(0), a1724. https://doi.org/
10.4102/sajip.v45i0.1724
Copyright:
○ 2019. The Authors.
Licensee: AOSIS. This work
is licensed under the
Creative Commons
Attribution License.

Problemification: This article identifies the drivers of and solutions to the replicability crisis for psychological science and the South African Journal of Industrial Psychology (SAJIP).

Implications: The article addresses and discusses possible starting points to tackle the recent replicability crisis and convert it into a chance for psychological research and the SAJIP.

Purpose: To combine a discussion about the replicability crisis and how it could improve psychological research standards and journal policies.

Recommendations: The article provides recommendation on how to change SAJIP's policies to increase international visibility.

Keywords: Replication crisis; Open science practices; Open science; Reproducibility crisis; Psychological research.

In this article, I will focus on and explain how the current replicability crisis in psychology can also be a chance for psychological research and, further, how it can be converted into a chance for the South African Journal of Industrial Psychology (SAJIP). Therefore, I will briefly provide readers with knowledge about my scientific background as it might be influencing my perspective on the replicability crisis. Furthermore, I will describe in what ways the crisis might even benefit SAJIP and how this conversion can be succeeded.

As my research is located at the intersection of social and organisational psychology, I am an active member in both communities and familiar with the ongoing debate about replicability in both fields, especially in the European context. From my perspective, both sub-disciplines and especially corresponding journals handle questions and concerns regarding replicability quite differently. After the investigations against Diederik Stapel, former professor of social psychology at Tilburg University, who manipulated and even created fictive data in his publications, the question of how to conduct good research and reduce the likelihood of fraudulence was very prominent in the psychological research, and researchers developed ideas on how research policies could be improved (Nosek et al., 2015). As a result, there have been several replication studies (Camerer et al., 2018), and a shift towards more transparency in conducting and publishing research has already been started (Van't Veer \& Giner-Sorolla, 2016). Thus, using the Open Science Framework (OSF), pre-registering studies and experiments, preprint publications and sharing the data or at least making data publicly available is nowadays common in the social psychology sector. Hence, questions like transparency of the research process, open access publications, pre-publications of manuscripts and the aim for reproducibility, replicability and equality are salient and prominent. In line with these developments, almost all social psychological journals have changed their policies correspondingly. However, in my experience, these questions are not so prominent in the organisational and business psychology sector. Although, there has been some discussion, debates and changes in some journal policies, in general, the scientific work in the organisational and business psychology sector has not changed as much as it is in the social psychology sector, and discussions about replication studies in organisational studies have just started (Köhler \& Cortina, 2019). All the more, I appreciate the recent article by Efendic and Van Zyl (2019) in SAJIP about this topic. In my opinion, the authors summarise very well several factors that contributed to the existing replicability crisis, and further outline some solutions regarding how to overcome critical aspects contributing to the crisis. 
I completely agree with the aspects stated by Efendic and Van Zyl (2019) of (1) statistical power and small sample sizes, (2) publication bias, (3) existing research practices and publication pressure, (4) existing incentive systems in academia and (5) lack of transparency as main drivers of the current crisis. Furthermore, like the authors, I think that power analyses, pre-registration of research and transparency regarding both data and statistical analyses are essential for avoiding fraudulence. From my perspective, establishing policies and guidelines for authors, which include these aspects and which value that researchers commit themselves to these research guidelines, would benefit the whole field of psychological research and should become common in all psychological sub-disciplines. An additional aspect that is not mentioned in Efendic and Van Zyl's (2019) article is the fairness component. By fairness I mean that individuals and especially researchers all over the world - independent of the country or university they are studying or working at should have access to state-of-the-art literature that is relevant for their own research, work or interest. This problem of no access without paying for the content of an article is referred to as pay gap ${ }^{1}$, and a further argument why authors and institutions should favour open access publications. However, based on the same argument, psychological associations in the national and international levels (e.g. American Psychology Association [APA], Society of Industrial and Organizational Psychology [SIOP], and European Association of Work and Organizational Psychology [EAWOP]) should create funds where researchers who work under such conditions that do not allow them to pay for open access publications can apply for financial support for open access publications. Thus, in several aspects, the recent crisis has impacted and is still impacting psychological research practices towards more transparency. But how can it also be a chance for SAJIP?

From my perspective, the crisis might trigger some changes in SAJIP policies and strategic decisions that on the long run could improve the publicity and visibility of SAJIP in the international community and might thereby support the inclusion in the Thomas Reuter Index (Institute for Scientific Information [ISI]) by attracting more international researchers. When looking at the results presented in the recent article by Efendic and Van Zyl (2019), the article of Coetzee and Van Zyl (2014) and further recent descriptive statistics (see Table 1) for gender, race and nationality diversity, origins of authors and collaboration status for volume 43 (2017) and volume 44 (2018) of SAJIP, certain domains for improvement become obvious. The statistics clearly show that there is no problem regarding gender diversity: female and male authors contributed almost equally to SAJIP. However, when looking at the race and nationality diversity of authors, the vast majority were white South African scholars (around 90\%).

Therefore, if SAJIP wants to gain a prominent status in the international community, it has to increase its visibility

1.Interested scholars can find more information about this rationale, for example, on the website https://paywallthemovie.com/ of the movie Paywall: The business of scholarship.
TABLE 1: Descriptive statistics for gender and race diversity, origin of authors and collaboration status in South African Journal of Industrial Psychology $(2018,2017)$.

\begin{tabular}{|c|c|c|}
\hline Category & 2018 (Vol. 44) & 2017 (Vol. 43) \\
\hline Number of authors per volume & $N=43$ & $N=36$ \\
\hline \multicolumn{3}{|l|}{ Gender diversity } \\
\hline Women & 25 & 19 \\
\hline Men & 18 & 17 \\
\hline \multicolumn{3}{|l|}{ Race/nationality diversity } \\
\hline White & 37 & 28 \\
\hline Black & 1 & 7 \\
\hline Indian & 1 & 1 \\
\hline Cape Malay & 0 & 0 \\
\hline Other & 0 & 0 \\
\hline \multicolumn{3}{|l|}{ Origin of authors } \\
\hline National & 41 & 29 \\
\hline International & 2 & 7 \\
\hline Number of publications per volume & $N=18$ & $N=17$ \\
\hline \multicolumn{3}{|l|}{ Collaborations per article } \\
\hline Publications with single institution authors & 12 & 9 \\
\hline Publications with multiple institution authors & 4 & 4 \\
\hline Publications with single authors & 2 & 4 \\
\hline
\end{tabular}

and get onto the main Thomas Reuter Index (ISI), and internationalisation and enhancing diversity might be good starting points in this regard. This could be achieved with an increase in international collaboration, which would not only lead to a more international authorship but also readership. In addition, collaborations are also one solution presented by Efendic and Van Zyl (2019) to avoid fraudulence. Therefore, international collaborations should be encouraged by the journal's policies. This could be achieved in a first step by having Special Issues (1) edited by invited international established scholars and (2) on topics that explicitly focus on cultural diversity aspects and/or comparisons between South Africa and other countries. This would also support the internationalisation of the journal and thereby strengthen its international visibility. Furthermore, SAJIP could overcome the problem of excluding (international) authors based on the fact that they are not able to pay the publication fee by (1) providing links on the journal's homepage to funding possibilities for authors, (2) establishing a transparent discount system for authors, for example, based on the country of origin or affiliation of the authors, (3) developing a system that allows discounts for authors who also act as reviewers for the SAJIP and (4) installing close networks with international membership associations (like SIOP or EAWOP) and implementing collaborations of the SAJIP and the outlet journals of international membership associations that might also contribute to a higher international visibility of the journal.

Furthermore, active participation of members of the editorial team in the open science conference and other open science network activities would boost the publicity of the journal both internationally and in the open science community.

Summing up, I think that a change in SAJIP's policies might benefit both the internationalisation of the journal and the 
establishment of research standards that could avoid fraudulence, are more transparent and are in line with the open science rationale.

\section{Acknowledgements}

The author thanks Llewelyn E. van Zyl for suggesting her to write this opinion article and discussing her ideas with him.

\section{Competing interests}

The author declares that she has no financial or personal relationships which may have inappropriately influenced her in writing this article.

\section{Author's contributions}

A.S.H.B. is the sole author of this research article.

\section{Ethical considerations}

This article followed all ethical standards for a research without direct contact with human or animal subjects.

\section{Funding information}

This research received no specific grant from any funding agency in the public, commercial or not-for-profit sectors.

\section{Data availability statement}

Data sharing is not applicable to this article as no new data were created or analysed in this study.

\section{Disclaimer}

The views and opinions expressed in this article are those of the author and do not necessarily reflect the official policy or position of any affiliated agency of the author.

\section{References}

Camerer, C.F., Dreber, A., Holzmeister, F., Ho, T.H., Huber, J., Johannesson, M., ... Altmejd, A. (2018). Evaluating the replicability of social science experiments in Nature and Science between 2010 and 2015. Nature Human Behaviour, 2(9), 637-644. https://doi.org/10.1038/s41562-018-0399-z

Coetzee, M., \& Van Zyl, L.E. (2014). A review of a decade's scholarly publications (2004-2013) in the South African Journal of Industrial Psychology. SA Journal of Industrial Psychology, 40(1), Art. \#1227. https://doi.org/10.4102/sajip.v40i1.1227

Efendic, E., \& Van Zyl, L.E. (2019). On reproducibility and replicability: Arguing for open science practices and methodological improvements at the South African Journal of Industrial Psychology. SA Journal of Industrial Psychology, 45(0), a1607. https:// doi.org/10.4102/sajip.v45i0.1607

Köhler, T., \& Cortina, J.M. (2019). Play it again, Sam! An analysis of constructive replication in the organizational sciences. Journal of Management. https://doi. org/10.1177/0149206319843985

Nosek, B.A., Alter, G., Banks, G.C., Borsboom, D., Bowman, S.D., Breckler, S.J., .. Contestabile, M. (2015). Promoting an open research culture. Science, 348(6242) 1422-1425. https://doi.org/10.1126/science.aab2374

Van't Veer, A.E., \& Giner-Sorolla, R. (2016). Pre-registration in social psychology A discussion and suggested template. Journal of Experimental Social Psychology, 67, 2-12. https://doi.org/10.1016/j.jesp.2016.03.004 